\title{
BRIDGING ENVIRONMENTAL IMPACT OF FOSSIL FUEL ENERGY: THE CONTRIBUTING ROLE OF ALTERNATIVE ENERGY
}

\author{
ADEKOMAYA OLUDAISI ${ }^{{ }^{*}}$, ADAMA KAYODE ${ }^{1}$, OKUBANJO AYODEJI ${ }^{2}$ \\ ${ }^{I}$ Department of Agricultural and Mechanical Engineering, Faculty of Engineering, College of \\ Engineering and Environmental Studies, Olabisi Onabanjo University, Ibogun Campus, Ifo, \\ Ogun State, Nigeria \\ ${ }^{2}$ Department of Computer and Electrical \&Electonics Engineering, Faculty of Engineering, \\ College of Engineering and Environmental Studies, Olabisi Onabanjo University, Ibogun \\ Campus, Ifo, Ogun State, Nigeria
}

\begin{abstract}
The demand for fossil fuel energy remains high amid challenges as it relates to its sustainability among the developing countries of the world. Nigeria remains one of the top consumption of fossil fuel energy considering the large deposit of hydrocarbon in some parts of the country. This energy has been widely used globally with attendant implication on climate and environmental crisis. In this study, attempts were made to portray the environmental impact of fossil fuel energy with attendant effect on global temperature and rising water level. Global warming, among other effect of climate change is now noticeable in all facet of the universe and key of the methodology employed in this work is to assess the existing mitigating strategy and recommend long-lasting approach as it relates to efficient energy use. Key of the conclusion from this work futures the development of municipal solid waste (MSW) as sustainable energy fuel.
\end{abstract}

Keywords: fossil fuel, climate change, renewable energy, greenhouse gas emission

\section{INTRODUCTION}

Researchers and scientists have foreseen the environmental impact of fossil fuel energy and the need to develop a clear-cut strategy to mitigate its aftermath effect in the face of rising water level and increasing ambient temperature. Climate change and its resulting effects is now rearing its ugly head in all ramification of human's life and the solution appears far-fetched. Part of the effects has surfaced in form of greenhouse gas and rising ambient temperature. Excessive burning of fossil fuels (coal, oil, and gas) energy remains the major sources of carbon emission globally and the trend may continue in the next decade if no clear efforts are geared toward revitalizing renewable energy in most developing countries. As reported by Liu, et al. [1], fossil fuels energy contribute largely to world energy usage and about $85 \%$ of total energy sourced globally are mainly from fossil fuel. Some other authors [2-4] have warned on the danger of depleting limited fossil fuel sources without developing a sustainable and alternative energy to replace the dwindling oil reserve. Meanwhile, the resultant pollution and emission emanating from fossil fuel exploration and production is another issue that have not been addressed in many oil producing countries. One of the key contributing factor to global warming is gas flaring and Nigeria is ranked as one of the leading gas emission globally. Part of the objective of the research work is to explore the potential of municipal solid waste (MSW) as a renewable energy source. Conversion of MSW to energy is a novel eco-friendly research that has attracted global attention. China has successfully developed

\footnotetext{
*Corresponding author, email: oludaisiyetunde@ gmail.com; adekomaya.oludaisi@ oouagoiwoye.edu.ng

(C) 2017 Alma Mater Publishing House
} 
MSW incineration and anaerobic digestion for waste conversion to energy. Alternative energy development in developing countries appears to be at the lowest ebb as no concrete masterplan is available in all relevant government agencies to harness the growth of the renewable energy. While Nigeria energy demand is increasing astronomically as depicted in Figure 1, gas-fired power plant accounts for about $40 \%$ of energy sources in Nigeria and the volume of gas required to energize power plants is another huge tasks that has not been achieved. Oil and gas energy as indicated in the plot remain a highly sought commodity for energy generation in African largest economy and the environmental implication of burning this energy remain a challenge in terms of management and environmental sustainability. A further study at the Figure 1 equally shows that hydro power energy source ranks second in energy contribution to the Nigerian energy grid. Although, hydro power could be seen as a renewable energy source, this medium seems not to have been fully prioritize in Nigeria as energy generated through this channel do not largely improve the overall energy requirement in Nigeria.

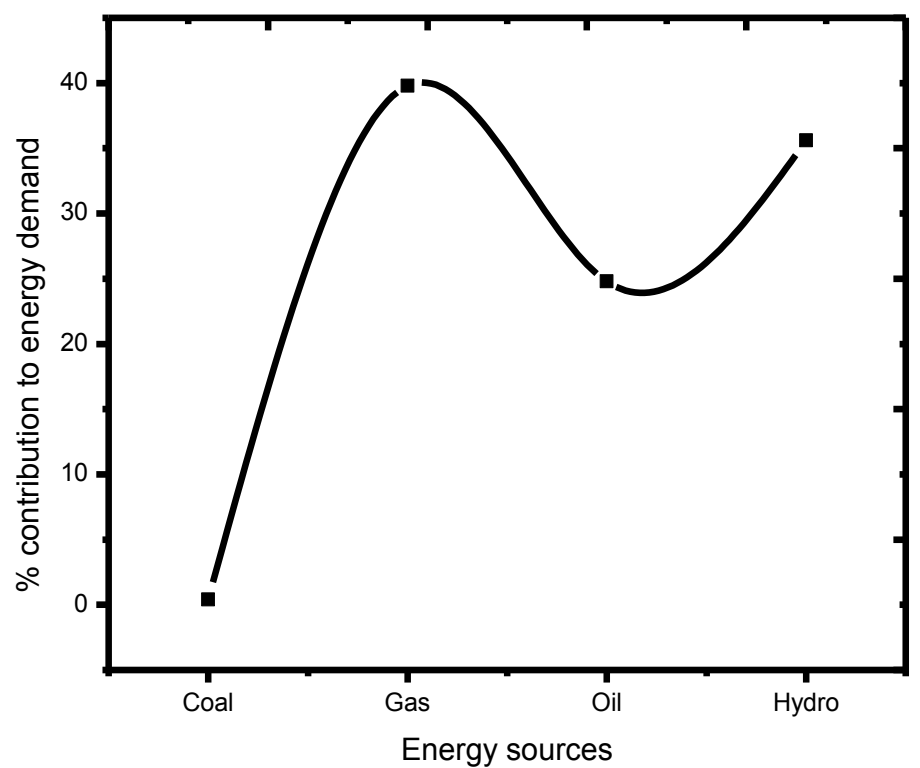

Fig. 1. Percentage contribution of different energy sources in Nigeria as of 2001 [5].

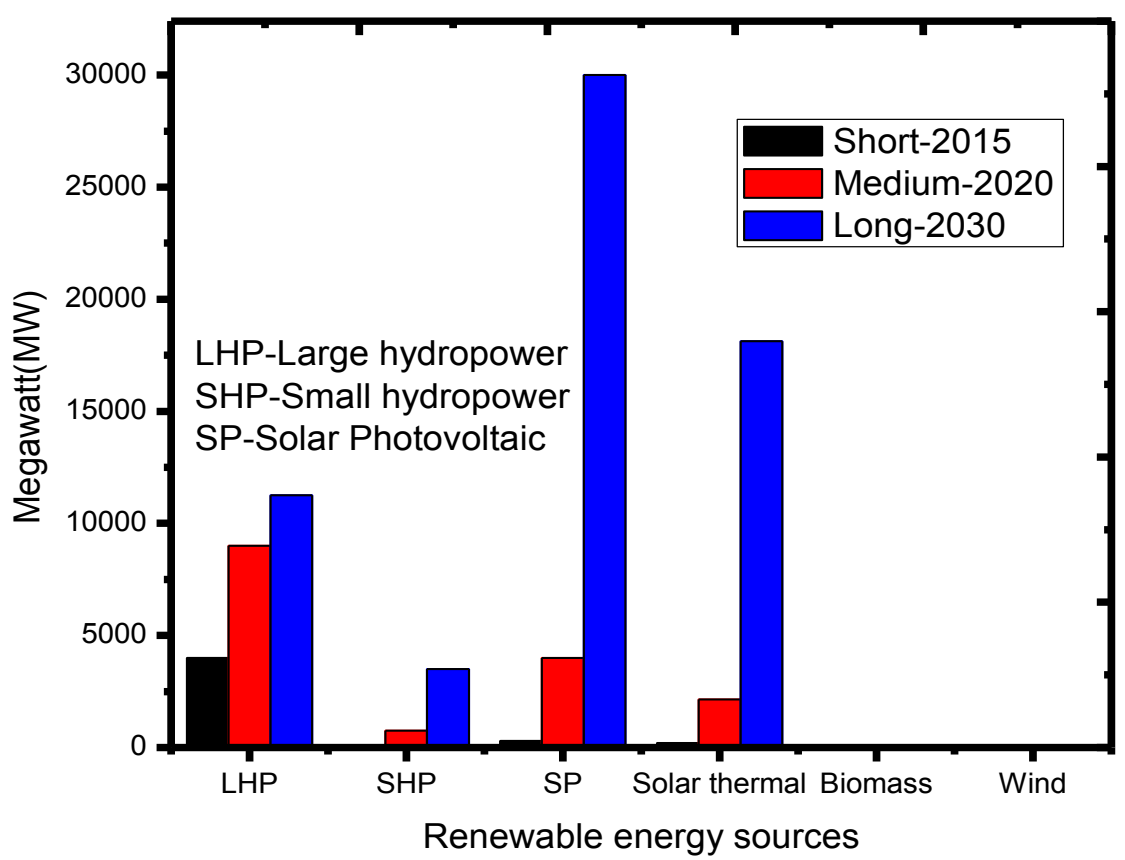

Fig. 2. Prospect of renewable energy in electricity generation in Nigeria [6]. 
The future outlook for renewable energy in Nigeria appear sceptical as government effort to divert attention from fossil fuel energy yield little patronage. Exploration of renewable energy for electricity generation remain a huge challenge as depicted in Figure 2. This particular figure portray the investment and utilization of various renewable energy sources in Nigeria on a short term, medium term and long term basis. From this figure, there is virtually no investment and utilization in biomass and wind energy sources in Nigeria and the long term prospect on these two energy sources remain unclear as nothing is currently on ground to justify investment in these two renewable energy sources. Large hydropower (LHP) remains the most sought-after among all the renewable energy sources in Nigeria as all the short, medium and long term investment plan remain focussed on this energy system. While it is important to develop large hydropower for energy improvement in Nigeria, this must be done with comprehensive plans to harmonise all renewable energy sources in Nigeria. According to Emodi and Boo [7], the development of reliable and clean energy system may entail detailed and exhaustive master plan taking into consideration conventional energy resources. This may also include among others, the effective support policies and robust participation by Nigerian government in clean energy development.

\section{ANALYSIS OF EXISTING MODELS ON ENERGY UTILIZATION}

Fossil fuels energy contain carbon and were developed through a geological processes over several million years ago and the key components of this energy were majorly from the remains of organic matter from plants and animals. In this study, past literature analysis on the impact of fossil fuel utilisation were adopted to form key data in this research. Figure 3 shows the contribution of fossil fuel energy to global energy supply and it can be seen that global energy supply will continue to rely on fossil energy as reported by Liu, et al. [1]. This report went further to conclude that fossil fuel energy will remain dominant till 2020 and could increase to $90 \%$ global energy need if sustainable measures are not put in place to develop other renewable energy in the world. In a related study, Zhang and Bauer [8] reported the emission factors of fossil fuel energy in China, being the highest fossil fuel dependent country in the world and the result of the research is shown in Figure 4. The implication of the result depicts that over the entire years of study, the aggregated emissions factor for fossil fuels increased astronomically and then declined as a result of energy mix adopted to reduce the rising emission factors of fossil fuel.

The emissions factor in 2010 was almost the same as in 1980 which signify the impact of renewable energy to combat the rising emission rate of fossil fuel. Nigeria energy need is predicted $[9,10]$ to rise in view of huge demand occasioned by rising population. Exploring other renewable energy has been a long-term solution to reduce overdependence on carbon based energy. These renewable energy has been largely abandoned as quantity of energy sourced from these sources remain at the lowest ebb. Table 1 shows the detailed potential energy sources in Nigeria and the percent energy utilised from these sources. While Nigeria remains a huge energy deposit globally, only fraction of these energy has been converted for real utilization. Depleting fossil fuel reserve in an emerging countries like Nigeria has a long implication on the climate and most importantly on biodiversity.

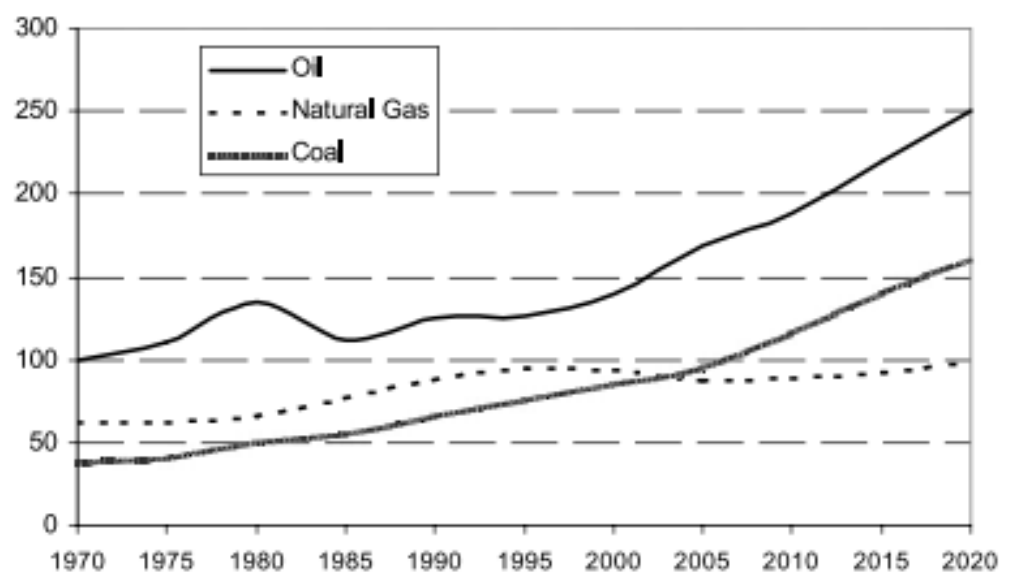

Fig. 3. Projected contribution of fossil fuel energy to global energy need [1]. 


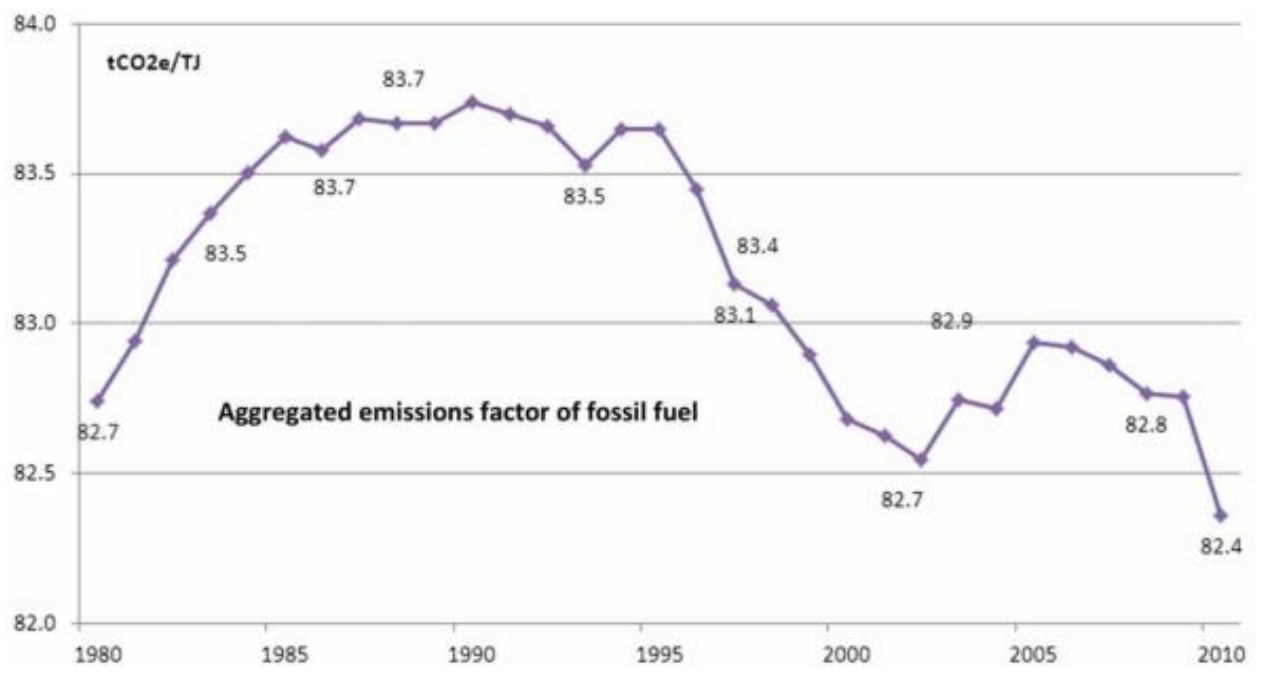

Fig. 4. Aggregated emission factor of fossil fuel energy in energy use. Adapted from Zhang and Bauer [8].

Table 1. Potentials for renewable energy sources in Nigeria [11].

\begin{tabular}{|l|l|l|}
\hline Renewable energy sources & \multicolumn{1}{|c|}{ Potentials } & \multicolumn{1}{|c|}{ Utilization } \\
\hline Large hydropower & $11,250 \mathrm{MW}$ & $2000 \mathrm{MW}$ utilized \\
\hline Small hydropower & $3500 \mathrm{MW}$ & $64 \mathrm{MW}$ exploited \\
\hline Solar & $4.0 \mathrm{kWh} / \mathrm{m}^{2}$ day & \multicolumn{1}{|c|}{ million tones/yr. fuel wood } \\
\hline Biomass & Fuel wood & $\begin{array}{l}28 \text { million hectares of arable land; } 8.5 \% \\
\text { cultivated }\end{array}$ \\
\hline & Energy crops & \\
\hline
\end{tabular}

According to Anomohanran [12], greenhouse gas emission has contributed to the increasing rate of climate weather changes in oil producing nations of the world. In a detailed analysis, the author demonstrated this effects as presented in Figure 5 showing the graphical illustration of gas flared in Nigeria from 1999 to 2009. Detailed analysis of data showed that the emission rate increased from 43.3 million metric tons in 1999 as against 50.2 million metric tons recorded in 2001 but reportedly dropped to 40.6 million metric tons in 2002 . Increasingly crude oil activity further pushed the emission rate to high level of 46.8 million metric tons in 2004 which also confirm the impact of crude oil activity on emission rate. Nigeria, being an oil dependent country still needs to do more to harmonise all laws relating to oil exploration in effort to curb emission resulting from gas flaring and other associated energy recovery.

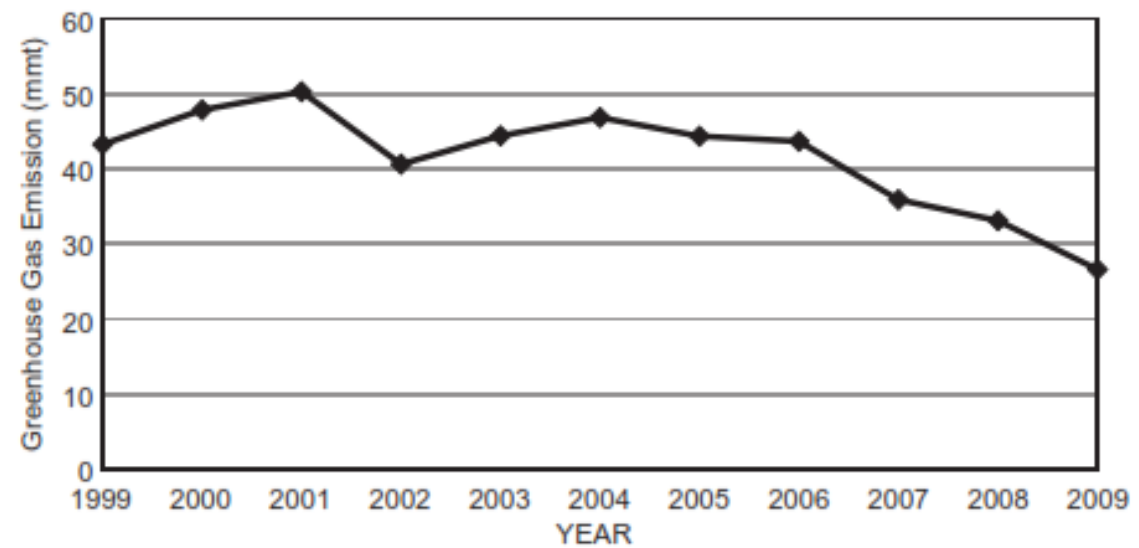

Fig. 5. Greenhouse gas emission emanating from oil exploration in Nigeria from 1999 to 2009 [12]. 


\section{DISCUSSION ON ALTERNATIVE ENERGY SOURCES AND THEIR PROSPECT FOR UTILIZATION}

Faced with the challenges of depleting fossil fuel reserves and the environmental crisis emanating from the uses of fossil fuels, it is therefore increasingly necessarily to find sustainable and clean fuels for future uses. In a broader interpretation, the concept "alternative fuels" may not just merely entails replacing fossil fuels, but encompasses the developmental effort of maintaining the existing biodiversity using cleaner energy. The adoption of sustainable energy fuel will certainly transcend the present generation if the world will continue to be safer for future generation. The impact of climate change is being felt in all facet of life with fossil fuel being one of the major contributing factors. Some authors [3,13] did report that cleaner fuels from renewable energy sources need to be harnessed with little demand on fossil fuels. This effort, according to the aforementioned authors, will promote climate sustainability and safer world. However, while efforts are on-going to replace the conventional fuels, government at all level needs to adopt culture that promotes environmental friendliness and sustainable development. Key of the potential substitutes for fossil fuel energy include biomass fuels, municipal solid waste, hydrogen, alcohols, nitrogen hydrides, and nitro-hyrocarbons. In other works, these fuels share one common feature: they are freely available and easily obtainable with little or no effort. Furthermore, in order to qualify as energy fuels, they must have properties that makes them to reserve energy. This characteristic qualify them to contain matter in adequate quantities for energy development. The search for sustainable energy revolve round biomass and municipal solid waste as these two sources of energy have not been properly managed in Nigeria and other part of Africa. Biomass is a renewable energy source and is mainly organic substitute to fossil fuel. Globally, biomass ranks fourth in terms of abundance among renewable energy, with the prospect of accounting for $15 \%$ of world energy use if properly harnessed in developing countries $[9,10,13]$. One of the key advantages of biomass energy are that they can be applied in other facet of life comparable to fossil fuels and also enjoy the patronage of existing technologies and are also acceptable to other electric utility users. Part of the disadvantages of biomass energy sources are their high moisture contents and ignite ash contents. Municipal solid waste (MSW) is also attracting attention as energy fuel in view of its availability and the inability of government to properly manage this segment of waste volume in proper perspective. In other words, MSW is municipal garbage and it consists of solid wastes from everyday items such as furniture, clothing, bottles, food scraps, newspapers, appliances, etc. One of the major use of MSW fuel is to generate electricity as witnessed in the United States, where a special MSW power plant has been developed to convert waste to energy. Key of the difficulty currently experienced in converting MSW to energy fuels is that MSW-derived fuels sometimes involves beneficiation, which may require the removal of some impurities or sewage sludge, which are still expensive to be adapted in developing countries as a power station. This barrier has been limiting mass-production of this fuel for energy use.

\section{CONCLUSIONS}

The current pattern of energy need and application has to be reviewed in our society to save the climate and the future generation. The continuation of fossil fuel energy use is a risk may consume the world in the near future as global warming continue to affect all living things adverse form. Sustaining the present biodiversity entails a cleaner energy and sustainable environmental impact. In this study, attention has been created to portray the prospect of two keys sustainable energy source for the future and there is need for government to take a proactive steps to combat the teething problems facing these two energy sources. In the meantime, it is also important to acknowledge that the shift to non-fossil fuels may likely be slow but attention should be shifted to develop a reliable roadmap that will kick-start this sector.

\section{ACKNOWLEDGMENT}

The lead author would like to appreciate various authors whose literatures provided details information that assisted in the composition of this manuscript. The authors also acknowledge various comments received from our colleagues in the university that have added value to this work.

\section{REFERENCES}

[1] Liu, L., Cheng, S., Li, J., Huang, Y., Mitigating environmental pollution and impacts from fossil fuels: The role of alternative fuels, Energy Sources, Part A, vol. 29, no. 12, 2007, p. 1069-1080.

[2] Dincer, I., Environmental impacts of energy, Energy Policy, vol. 27, 1999, p. 845-854. 
[3] Kalaivani, K., Balasubramanian, N., Energy Consumption and Greenhouse Gas Emission Studies of Jatropha Biodiesel Pathway by Life Cycle Assessment in India, Indian Chemical Engineer, 2015, p. 1-13.

[4] Martindale, W., Carbon, food and fuel security-will biotechnology solve this irreconcilable trinity?, Biotechnology and Genetic Engineering Reviews, vol. 27, 2010, pp. 115-134.

[5] Aliyu, A.S., Dada, J.O., Adam, I.K., Current status and future prospects of renewable energy in Nigeria, Renewable and Sustainable Energy Reviews, vol. 48, no. 8, 2015, p. 336-346.

[6] Bala, E., Renewable energy policy \& masterplan for Nigeria, Energy Commission of Nigeria; Available from: http://wwwenergygovng/indexphp, 2012.

[7] Emodi, N.V., Boo, K.J., Sustainable energy development in Nigeria: Current status and policy options, Renewable and Sustainable Energy Reviews, vol. 51, no. 11, 2015, p. 356-381.

[8] Zhang, S., Bauer, N., Utilization of the non-fossil fuel target and its implications in China, Climate policy, vol. 13, 2013, p. 328-344.

[9] Balat, M., Energy and greenhouse gas emissions: A global perspective, Energy Sources, Part B, vol. 1, 2006, p. $157-170$.

[10] Hutter, H.P., Kundi, M., Moshammer, H., Shelton, J., Krüger, B., Schicker, I., Replacing fossil diesel by biodiesel fuel: Expected impact on health, Archives of environmental \& occupational health, vol. 70, 2015, p. 49.

[11] Maji, I.K., Does clean energy contributes to economic growth? Evidence from Nigeria, Energy Reports, vol. 1 , no. 11,2015 , p. $145-150$.

[12] Anomohanran, O., Determination of greenhouse gas emission resulting from gas flaring activities in Nigeria, Energy Policy, vol. 45, no. 6, 2012, p. 666-670.

[13] Lue, A., Bresciani, C., Colorni, A., Lia, F., Maras, V., Radmilovic, Z., Future priorities for a climatefriendly transport. A European Strategic Research Agenda towards 2030, International Journal of Sustainable Transportation, 2014. 